\title{
Therapy With Interferon- $\alpha$ Plus Ribavirin for Membranoproliferative Glomerulonephritis Induced by Hepatitis C Virus
}

Edmundo P.A. Lopes ${ }^{1}$, Lucila M. Valente ${ }^{2}$, A. Eduardo B. Silva ${ }^{1}$, Gianna Mastroianni Kirsztajn ${ }^{2}$, Cibele N. Cruz ${ }^{1}$ and Maria Lucia G Ferraz ${ }^{1}$
Divisions of Gastroenterologyl and Nephrology, Department of Medicine, São Paulo Medical School, Federal University of São Paulo, São Paulo, SP, Brazil

\begin{abstract}
We describe a treatment made with interferon- $\alpha($ IFN- $\alpha)$ plus ribavirin of two patients with membranoproliferative glomerulonephritis (MPGN) induced by hepatitis $\mathrm{C}$ virus (HCV): Case 1 was a 22-year-old woman with leg and facial edema, hypertension and proteinuria, whose liver biopsy revealed chronic active hepatitis; and Case 2 was a 42-year-old man with anasarca, hypertension and proteinuria, whose liver biopsy indicated cirrhosis. Both had anti-HCV, HCVRNA and cryoglobulins. IFN- $\alpha$ ( 3 million units (MU), 3 times/week) and ribavirin ( $1 \mathrm{~g} / \mathrm{day}$ ) were administered for 12 months. The drugs were well tolerated by both patients. Serum alanine aminotransferase (ALT) levels normalized and HCV-RNA became negative. Cryoglobulins disappeared and an improvement in renal disease was seen after 6 months of therapy. However, after 9 months, Case 2 presented ALT elevation, and proteinuria was detected. Two years after the end of therapy, both patients were negative in repeated HCV-RNA and cryoglobulin tests. Case 1 was asymptomatic, with normal liver and renal tests, and Case 2 had normal blood pressure, with mild edema of the ankles. Based on the evolution of these two cases, the association of IFN- $\alpha$ and ribavirin may be a therapeutic option for patients with MPGN related to HCV.

Key Words: Glomerulonephritis, hepatitis $\mathbf{C}$, interferon, ribavirin.
\end{abstract}

Hepatitis $\mathrm{C}$ virus (HCV) is associated with several extrahepatic manifestations. Mixed cryoglobulinemia (MC) is the most common, being detected in about $50 \%$ of the cases [1,2]. Some researchers have reported that approximately $15 \%$ of patients with $\mathrm{HCV}$ and MC also present glomerulonephritis, particularly membranoproliferative glomerulonephritis (MPGN) [2-5].

In adults, most patients with primary or secondary MPGN have a poor outcome, progressing to renal failure [6]. The diagnosis of a secondary disease in patients with glomerulonephritis assumes special importance, particularly in the cases of HCV infection, since it can Received on 10 March 2003; revised 11 July 2003.

Address for correspondence: Dr..Edmundo P.A. Lopes. Estrada das Ubaias, 311 - Apto. 901-A - Casa Forte, Zip code:52061080 - Recife, PE- Brazil. Phone: (55 81) 3441-3494. Fax: (55 81) 3442-0400.E-mail: epalopes@ufpe.br

The Brazilian Journal of Infectious Diseases 2003;7(5):353-357 (C) 2003 by The Brazilian Journal of Infectious Diseases and Contexto Publishing. All rights reserved. lead to changes in the therapeutic approach. In fact, protocols of treatment of glomerulonephritis induced by $\mathrm{HCV}$, using interferon- $\alpha$ (IFN- $\alpha$ ), have produced remission of proteinuria, concomitantly with virological response during therapy, but a high rate of relapse of liver and kidney diseases was observed after stopping drug usage [7, 8]. Other studies have also shown clinical improvement in patients with MPGN induced by HCV during treatment with ribavirin, but recurrence occurred in almost all patients after drug discontinuation $[9,10]$.

During the last few years, some trials have demonstrated that the administration of IFN- $\alpha$ plus ribavirin to patients with chronic hepatitis $\mathrm{C}$ infections gives much better results than those observed with the use of each one alone [11]. In fact, Misiani et al. [12] and Garini et al. [13] described a good response by three patients who were treated with a combination of IFN plus ribavirin for $\mathrm{HCV}$-induced MPGN. We describe here two more patients with MPGN induced by HCV who had improvement of hepatic and renal diseases after treatment with IFN- $\alpha$ plus ribavirin. 


\section{Case Reports}

Case 1. A 22-year-old woman, with a history of edema of the legs and face since 2 months before admission, who used furosemide and nifedipine daily, was referred for evaluation. On physical examination, she presented edema and hypertension $(180 / 100 \mathrm{~mm}$ $\mathrm{Hg}$ ). Her medical history was unremarkable, but she had received a blood transfusion 21 years before. The main laboratory data were: $2.5 \mathrm{~g}$ /day proteinuria, numerous dysmorphic erythrocytes in the urine (100 red blood cells per high-power field) and $1.3 \mathrm{mg} / \mathrm{dL}$ serum creatinine. Serum alanine aminotransferase was mildly elevated (alanine aminotransferase $(\mathrm{ALT})=35$ $\mathrm{U} / \mathrm{mL}$; AST normal), anti-HCV antibodies and HCVRNA were both positive, and the HCV genotype was 1b. HBV markers were negative. The serum levels of cryoglobulins were $243 \eta \mathrm{g} / \mathrm{mL}$ (type II). Renal biopsy revealed MPGN, and the liver biopsy showed chronic active hepatitis. Treatment with IFN- $\alpha$ plus ribavirin was indicated.

Case 2. A 42-year-old man with a history of edema of the legs that progressed to anasarca during the previous 3 months was referred. The patient was previously an intravenous drug addict. On physical examination, he presented anasarca and hypertension (150/100 mm Hg). The main laboratory data were: 1.3 $\mathrm{g} /$ day proteinuria, numerous dysmorphic erythrocytes in urine (100 red blood cells per high-power field) and 1.9 $\mathrm{mg} / \mathrm{dL}$ serum creatinine. Serum aminotransferases were elevated $(\mathrm{ALT}=53 \mathrm{U} / \mathrm{mL} ; \mathrm{AST}=60 \mathrm{U} / \mathrm{mL})$; anti-HCV antibodies and HCV-RNA were both positive, and the HCV genotype was 3a. The serum levels of cryoglobulins were $186 \eta \mathrm{g} / \mathrm{mL}$ (type II). Renal biopsy revealed MPGN and the liver biopsy showed active cirrhosis. It was decided to treat him with IFN- $\alpha$ plus ribavirin.

\section{Materials and Methods}

Anti-HCV antibodies were measured using a second-generation enzyme immunoassay (Abbott Laboratories) and the serum HCV-RNA was investigated using a nested-PCR, as described by
Shindo et al. [14]. Genotyping was performed by sequence analysis of a portion of the 5' untranslated region of the HCV genome [15]. Cryoglobulins were identified by immunoelectrophoresis, with specific antibodies against immunoglobulins, and quantified by the Lowry method. In both cases, other possible causes of glomerulonephritis were excluded, such as diabetes, systemic lupus erythematosus, lues, schistosomiasis mansoni, and malignancies.

Three million units (MU) of IFN- $\alpha 2 b$ were administered subcutaneously, 3 times a week, and $1 \mathrm{~g} /$ day of ribavirin was taken orally, both during 12 months. The patients were evaluated monthly during the treatment and were followed up till 24 months after the end of therapy.

\section{Results}

Both patients tolerated well the combination therapy. There was a slight decrease in the hemoglobin levels and a rise in the number of reticulocytes, which normalized spontaneously after treatment was completed. After the beginning of the therapy, Case 1 had a regression of the edemas and gradual control of blood pressure levels, allowing the interruption of antihypertensive drugs. At the third month of therapy, she presented normalization of ALT serum levels, HCVRNA became negative, and cryoglobulins and proteinuria levels decreased (Figure 1).

These parameters persisted without significant changes until the end of therapy. At 24 months after stopping therapy, she continued to be asymptomatic, without using any medication; serum ALT levels were normal, cryoglobulins and HCV-RNA test were negative. There were also no urinary abnormalities. Contraceptive methods were stopped and the patient became pregnant.

After the beginning of therapy, Case 2 had reduced edema, and he needed less antihypertensive drugs. By the sixth month, he had normal serum aminotransferase levels, the HCV-RNA test became negative, and serum levels of cryoglobulins and proteinuria decreased. However, by the ninth month, the levels of aminotransferases increased and proteinuria was 
Figure 1. Laboratory data of Case 1 of hepatitis $C$ virus-induced membranoproliferative glomerulonephritis during therapy with interferon- $\alpha$ (3 million units, 3 times a week) plus ribavirin (1g/day), and follow-up. Serum levels of alanine aminotransferase (ALT) and cryoglobulinemia are expressed as the value above the upper limit of normal; proteinuria is expressed as $\mathrm{g} / 24$ hours.

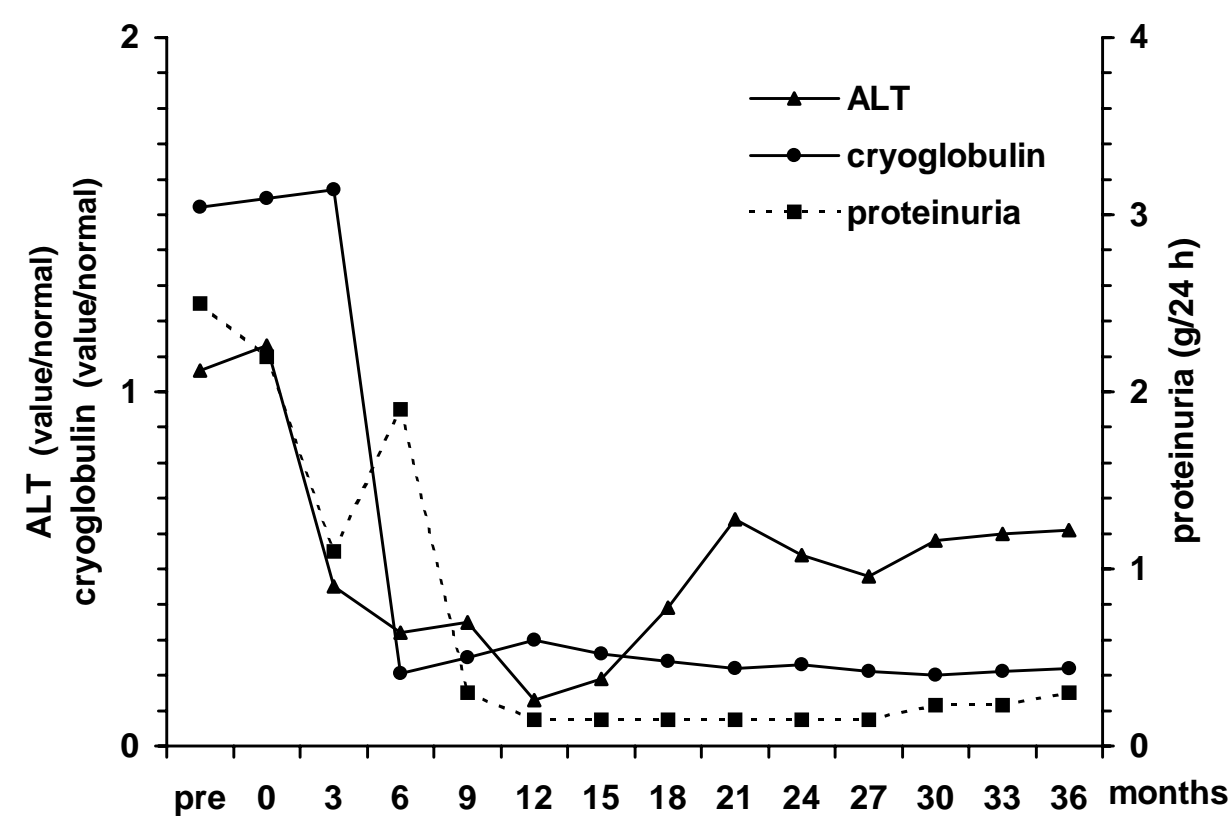

Figure 2. Laboratory data of Case 2 during therapy with interferon- $\alpha$ ( 3 million units, 3 times a week) plus ribavirin (1g/day) and follow-up. Serum levels of alanine aminotransferase (ALT) and cryoglobulinemia are expressed as the value above the upper limit of normal; proteinuria is expressed as $\mathrm{g} / 24$ hours.

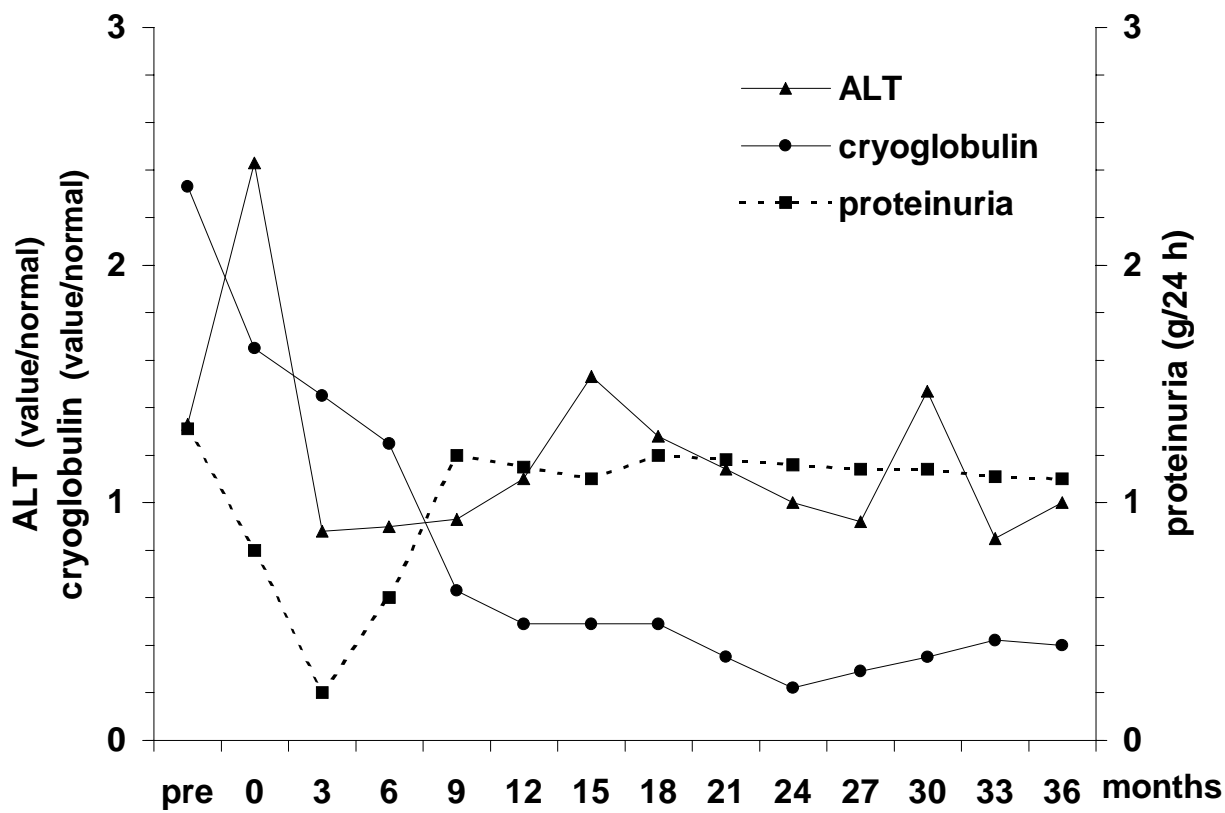


detected, although cryoglobulinemia and HCV-RNA remained negative (Figure 2). Twenty-four months after the end of the therapy, he presented a mild edema of ankles and his hypertension was under control, using $25 \mathrm{mg} /$ day spironolactone. The serum AST was mildly elevated $(52 \mathrm{U} / \mathrm{mL}), \mathrm{HCV}-\mathrm{RNA}$ and cryoglobulinemia were negative, and proteinuria was still present ( $1.1 \mathrm{~g} /$ day $)$.

\section{Discussion}

IFN- $\alpha$ has antiviral activity and it is being used in the management of viral hepatitis, as well as in the treatment of the extrahepatic manifestations related to HCV [7,11]. However, long-term biochemical, virological and histological improvements with the use of IFN- $\alpha$ alone is observed in less than $20 \%$ of patients [11]. In fact, Johnson et al. [7] treated 14 patients who had chronic active hepatitis $\mathrm{C}$ and MPGN with IFN$\alpha$, and observed a decrease in proteinuria as well as in serum aminotransferases and viremia. But the favorable effect of this therapy was observed only during the drug administration period. Sarac et al. [16] treated a patient with cryoglobulinemic MPGN, induced by HCV, with high doses of IFN- $\alpha$ (10 MU daily, during 2 weeks, followed by $10 \mathrm{MU}$ on alternate days during more 6 weeks); The patient still had a virological response a year after the end of the therapy. A second renal biopsy showed histological improvement. The authors suggested that is possible to reach and maintain hepatic and renal improvement with high doses of IFN- $\alpha$, though this is frequently poorly tolerated. Additionally, Wilson [17] described the benefit of long-term IFN- $\alpha$ therapy, during 5 years, for symptomatic mixed cryoglobulinemia in a patient with cutaneous vasculitis and MPGN induced by hepatitis C. He reported that therapy with interferon for a long period is effective, however the patient developed several side effects.

Given the limited results using only IFN- $\alpha$ in the treatment of hepatitis $\mathrm{C}$, other drugs have been proposed, such as ribavirin, a guanosine analog with antiviral activity. In trials involving patients with chronic hepatitis $\mathrm{C}$, the use of ribavirin decreased serum levels of ALT, but relapses occurred after stopping the drug $[18,19]$. Moreover, we treated a patient with HCVinduced cryglobulinemic MPGN with ribavirin alone, and observed an improvement of hepatic and renal disease at the end of the treatment. However, 2 months after the end of the treatment, there was a new increase in proteinuria, and the ALT levels became similar to those before treatment [9]. In addition, Pham et al. treated 4 patients submitted to liver transplantation, who presented nephrotic syndrome secondary to HCV-related MPGN, with ribavirin alone. They observed a decrease in proteinuria in the 4 cases, but after the drug treatment was stopped, proteinuria recurred in 2 patients. After reintroduction of ribavirin, the patients again showed a favorable response [10].

Nowadays, several studies suggest that an association of these two drugs, IFN- $\alpha$ and ribavirin, amplifies their therapeutic effects against HCV and leads to a higher frequency of sustained response, around $40 \%[11,20]$. Additionally, it is generally agreed that the initial therapy of chronic hepatitis $\mathrm{C}$ should be made with IFN- $\alpha$ plus ribavirin [20]. Recently, the first case of MPGN induced by HCV was reported to be successful treated with this combination [12].

We followed two other patients who were submitted to therapy with IFN- $\alpha$ plus ribavirin (this study). A sustained response was observed in Case 1 during 24 months after the treatment was stopped. The other patient had an adequate response during the first 9 months of therapy but subsequently proteinuria and a rise in serum aminotransferases were observed. However, he experienced clinical improvement of the edema and systemic hypertension. Twenty-four months after the end of the treatment, the patient maintained a discreet edema of the ankles, using only a small dose of diuretic, with no signs of cryoglobulins and was negative for serum HCV-RNA. Our experience with these patients lead us to believe that IFN- $\alpha$ plus ribavirin is a useful alternative treatment for the management of $\mathrm{HCV}$-induced MPGN. Further studies with more patients, or using pegylated IFN- $\alpha$, should be carried out to determine the true benefit of this therapy. 


\section{References}

1. Kayali Z., Buckwold V.E., Zimmerman B., Schmidt W.N. Hepatitis C, cryoglobulinemia, and cirrhosis: A metaanalysis. Hepatology 2002;36:978-85.

2. Beddhu S., Bastacky S., Johnson J.P. The clinical and morphologic spectrum of renal cryoglobulinemia. Medicine 2002;81:398-409.

3. Yamabe H., Johnson R.J., Gretch D.R., et al. Hepatitis C virus infection and glome-rulonephritis membranoproliferative in Japan. J Am Soc Nephrol 1995;6:220-3.

4. D'Amico G.. Renal involvement in hepatitis C infection: Cryoglobulinemic glomerulonephritis. Kidney Int 1998;54:650-71.

5. Lopes L.M.V., Lopes E.P.A., Silva A.E., et al. Glomerulonefrite associada à infecção pelo vírus da hepatite C. Rev Soc Bras Med Trop 1999;32:1-6.

6. Donadio J.V., Offord P.K. Reassessment of treatment results in membranoproliferative glomerulonephritis, with emphasis on life-table analysis. Am J Kidney Dis 1989; 14:445-51.

7. Johnson R.J., Gretch D.R., Couser W.G., et al. Hepatitis C virus-associated glomerulonephritis. Effect of $\alpha$ interferon therapy. Kidney Int 1994;46:1700-4.

8. Misiani R., Bellavita P., Fenili D., et al. Interferon alfa-2a therapy in cryoglobulinemia associated with hepatitis C virus. N Engl J Med 1994;330:751-6.

9. Lopes E., Lopes L.V., Silva A.E. Mixed cryoglobulinemia and membranoproliferative glomerulonephritis associated with hepatitis $C$ virus infection. Ann Intern Med 1996; $125: 781-2$.

10. Pham H.-P., Féray C., Samuel D., et al. Effects of ribavirin on hepatitis $\mathrm{C}$-associated nephrotic syndrome in four liver transplant recipients. Kidney Int 1998;54:1311-9.

11. McHutchison J.G., Gordon S.C., Schiff E.R., et al. Interferon alfa- $2 \mathrm{~b}$ alone or in combination with ribavirin as initial treatment for chronic hepatitis C. N Engl J Med 1998;339:1485-92.

12. Misiani R., Bellavita P., Baio P., et al. Successful treatment of $\mathrm{HCV}$-associated cryoglobulinaemic glomerulonephritis with a combination of interferon$\alpha$ and ribavirin. Nephrol Dial Transplant 1999; $14: 1558-60$.

13. Garini G., Allegri L., Carnevali W., et al. Interferon-alpha in combination with ribavirin as initial treatment for hepatitis C virus-associated cryoglobulinemic membranoproliferative glomerulonephritis. Am J Kidney Dis 2001;38:E35.

14. Shindo M., Di Bisceglie A.M., Cheung L., et al. Decrease in serum hepatitis $\mathrm{C}$ viral RNA during alfa-interferon therapy for chronic hepatitis C. Ann Intern Med 1991;115:700-4.
15. Germer J.J., Rys P.N., Thorvilson J.N., Persing D.H. Determination of hepatitis $\mathrm{C}$ virus genotype by direct sequence analysis of products generated with the Amplicor HCV test. J Clin Microbiol 1999;37:2625-30.

16. Sarac E., Bastacky S., Johnson J.P. Response to highdose interferon- $\alpha$ after failure of standard therapy in MPGN associated with hepatitis $C$ virus infection. Am J Kidney Dis 1997;30:113-5.

17. Wilson R.A. The benefit of long-term interferon alfa therapy for symptomatic mixed cryoglobulinemia (cutaneous vasculitis/membranoproliferative glomerulonephritis) associated with chronic hepatitis C infection. J Clin Gastroenterol 2001;33:137-40.

18. Zoulim F., Haem J., Si Ahmed S., et al. Ribavirin monotherapy in patients with chronic hepatitis C: A retrospective study of 95 patients. J Viral Hepatitis 1998;5:193-8.

19. Felipe M., Silva A.E.B., Lopes E.P.A., et al. A prospective and randomized study using ribavirin as monotherapy for the treatment of naive patients with chronic hepatitis C. Braz J Infect Dis 2000;4:183-91.

20. Di Bisceglie A., McHutchison J., Rice C.M. New therapeutic strategies for hepatitis C. Hepatology 2002;35:224-31. 